\title{
The Corrosion Behavior of Sputter-deposited W-Cr-(4-15)Ni Alloys in $\mathrm{NaOH}$ Solutions
}

\author{
Pom Lal Kharel and Jagadeesh Bhattarai* \\ Central Department of Chemistry, Tribhuvan University, GPO Box 2040, Kathmandu, Nepal. \\ e-mail:bhattarai_05@yahoo.com
}

\begin{abstract}
The synergistic effect of chromium addition in the sputter-deposited amorphous or nanocrystalline $\mathrm{W}-\mathrm{Cr}-(4-15) \mathrm{Ni}$ alloys is studied in alkaline $\mathrm{NaOH}$ solutions at $25^{\circ} \mathrm{C}$, open to air using immersion tests and electrochemical measurements. In $1 \mathrm{M} \mathrm{NaOH}$ solution, the addition of chromium to $\mathrm{W}$-Cr-(4-15)Ni alloys containing 42-75 at\% chromium increased the corrosion resistance and shifted the open circuit potential more noble so as to show higher corrosion resistance than those of alloy-constituting elements (that is, tungsten, chromium and nickel). The corrosion rates (that is, about $2-5 \times 10^{-3} \mathrm{~mm} . \mathrm{y}^{-1}$ ) of all the examined $\mathrm{W}$-Cr-(4-15)Ni alloys are about two orders of magnitude lower than that of tungsten and nearly one order of magnitude lower than that of chromium metal. The open circuit potential of the W-Cr-(4-15)Ni alloys is generally increased with increasing chromium content in different concentrations of $\mathrm{NaOH}$ solutions. The passivity of the $\mathrm{W}$ $\mathrm{Cr}$-(4-15)Ni alloys is increased with decreasing the concentration of $\mathrm{NaOH}$ solutions at $25^{\circ} \mathrm{C}$.
\end{abstract}

Keywords: Corrosion resistance, sputter deposition, $\mathrm{W}-\mathrm{Cr}$-Ni alloys, $\mathrm{NaOH}$ solutions, open circuit potential

\section{Introduction}

Corrosion is an inevitable process. As new engineering materials are developed, they need to have improved corrosion properties. The lack of corrosion-resistant properties of the engineering materials will be the cause of wastage of much money, labor as well as deterioration in the quality of such materials in a short time. Therefore, the works of engineering become unreliable without testimony of corrosion properties of materials. Early in the $20^{\text {th }}$ century, engineers did not take into consideration the importance of corrosion science during the initial designing of the materials with the thought that the problems arising from corrosion could be avoided by additional surface treatments. Whenever novel materials are developed, their industrial applications depend on the corrosion behavior over extended periods of service. The corrosion problems should be considered at an appropriate

${ }^{*}$ Corresponding author 
stage of the materials development, and hence corrosion research is also a part of engineering. ${ }^{1}$ In general, two things are to be significantly taken into mind before the engineering materials are subjected for application. Firstly, under what conditions it is used and secondly, how it is processed.

In recent, the corrosion scientists have to play significant role to develop such corrosion-resistant engineering materials. A series of new metastable amorphous or/and nanocrystalline single-phase solid solutions were developed using various techniques like vapor quenching, electrodeposition, mechanical alloying and so on. Among these techniques, the vapor quenching method is one of the widely used methods to prepare a homogeneous mixture of components. The sputter deposition technique is one of the main methods of vapor quenching and used as one of the potential techniques for the preparation of varieties of amorphous or/and nanocrystalline alloys. ${ }^{2}$ In recent years, this technique is known to form amorphous or nanocrystalline structures over the widest composition range among the various methods. Therefore, the use of sputter deposition technique is quite suitable for tailoring of the corrosion-resistant metastable alloys. Furthermore, even if amorphous alloys are not formed by this technique, the alloys thus prepared are always composed of nanocrystals with very fine grains (that is, less than $20 \mathrm{~nm})^{3}$ and sometimes behaves similar to the single-phase amorphous alloys. ${ }^{4}$ In particular, sputtering is suitable for forming alloys when the boiling point of one of the alloying component is lower than the melting point of the other alloying components, because sputter deposition does not require melting of alloying components for the alloy formation. For instance, boiling points of chromium $\left(2670^{\circ} \mathrm{C}\right)$ and nickel $\left(2900^{\circ} \mathrm{C}\right)$, which are far lower than the melting point of tungsten $\left(3420^{\circ} \mathrm{C}\right)$. However, successful attempts have been reported by one the present authors to prepare single-phase amorphous or/and nanocrystalline $\mathrm{W}-\mathrm{Cr}^{5}, \mathrm{~W}-\mathrm{Ni}^{6,7}$ and $\mathrm{W}$ $\mathrm{Cr}-\mathrm{Ni}^{8}$ alloys by using the advantages of sputtering.

Tungsten, chromium and nickel are known as effective alloying elements in enhancing the corrosion resistance of alloys in aggressive environments. In particular, tungsten and chromium are one of the most effective alloying elements to provide a high passivating ability for conventional steels. It has been reported that only small amount of tungsten addition (that is, less than 10 at\%) was enough to cause spontaneous passivation of the sputter-deposited nanocrystalline W-Cr alloys even in $12 \mathrm{M} \mathrm{HCl}$ at $30^{\circ} \mathrm{C}$ and these alloys showed lower corrosion rate than those of alloy-constituting elements. ${ }^{9,10}$ Similarly, it has been reported that the sputter-deposited amorphous or/and nanocrystalline W-Ni alloys were passivated spontaneously and tungsten addition greatly enhanced the corrosion resistance of nickel in $12 \mathrm{M} \mathrm{HCl}^{7}$ One of the present authors has been reported that the sputter-deposited tungsten-rich $\mathrm{W}-9 \mathrm{Ni}$ alloy showed the pitting corrosion although the nickel-rich W-Ni alloys containing 60 at $\%$ nickel or more showed higher corrosion resistance than those of tungsten and nickel in alkaline $\mathrm{NaOH}$ solutions. ${ }^{11}$ It is noteworthy for mentioning here that both chromium ${ }^{12}$ and nickel ${ }^{13}$ metals are very corrodible in acidic or very alkaline $(>13 \mathrm{pH})$ solutions containing oxidizing agents. However, both chromium and nickel metals do not generally corrode in slightly alkaline oxidizing solutions like $1 \mathrm{M} \mathrm{NaOH}$, mostly due to the formation of chromium hydroxide/oxides ${ }^{12}$ and nickel hydroxide/oxides ${ }^{13}$, respectively. On the other hand, tungsten metal is actively dissolved even in slightly alkaline solution as well as in solution having $\mathrm{pH}$ of 4 or high. ${ }^{14}$ Accordingly, it might be expected that effects of 
tungsten, chromium and nickel additions enhance in the corrosion resistance of the sputterdeposited amorphous or nanocrystalline $\mathrm{W}-\mathrm{Cr}-(4-15) \mathrm{Ni}$ alloys in $\mathrm{NaOH}$ solutions.

The present work aims to clarify the effects of tungsten, chromium and nickel additions on the corrosion behavior of the ternary $\mathrm{W}-\mathrm{Cr}-(4-15) \mathrm{Ni}$ alloys in alkaline $\mathrm{NaOH}$ solutions at $30^{\circ} \mathrm{C}$, open to air using immersion tests and electrochemical measurements.

\section{Experimental Methods}

The sputter-deposited ternary W-Cr-(4-15)Ni alloys containing 42-75 at\% chromium were characterized as single-phase solid solutions of amorphous or/and nanocrystalline structures having apparent grain size ranges from 1.5 to $10.2 \mathrm{~nm}$ as shown in Table $1{ }^{8}$ The compositions of the sputter-deposited W-Cr-(4-15)Ni alloys hereafter are all denoted in atomic percentage (at\%).

Table 1: Structure and apparent grain size of the sputter-deposited W-Cr-(4-15)Ni alloys. ${ }^{8}$

\begin{tabular}{|llc|}
\hline Name of Alloy & Structure & Apparent Grain Size (nm) \\
\hline W-42Cr-5Ni & amorphous + nanocrystalline & 3.5 \\
W-63Cr-15Ni & amorphous & 1.6 \\
W-67Cr-9Ni & amorphous & 1.5 \\
W-75Cr-4Ni & amorphous + nanocrystalline & 10.2 \\
Tungsten & nanocrystalline & 20 \\
Nickel & nanocrystalline & 19 \\
Chromium & nanocrystalline & 40 \\
\hline
\end{tabular}

Prior to the corrosion tests and electrochemical measurements, the W-Cr-(4-15)Ni alloys specimens were mechanically polished with a silicon carbide paper up to grit number 1500 in cyclohexane, degreased by acetone and dried in air. The average corrosion rate of the alloys was estimated from the weight loss after immersion for $168 \mathrm{~h} \mathrm{in} 1 \mathrm{M} \mathrm{NaOH}$ at $25^{\circ} \mathrm{C}$, open to air. The time dependence of the corrosion rate of the $\mathrm{W}-\mathrm{Cr}-(4-15) \mathrm{Ni}$ alloys was also estimated at various time intervals ranging from 2 to 168 hours. The weight loss measurement for each alloy specimens was done two times or more and the average corrosion rate of individual alloy was estimated.

The open circuit potentials of the ternary $\mathrm{W}-\mathrm{Cr}-(4-15) \mathrm{Ni}$ alloys were measured after immersion for 2 hours in $0.01,0.1$ and $1 \mathrm{M} \mathrm{NaOH}$ solutions at $25^{\circ} \mathrm{C}$, open to air. A platinum mesh and saturated calomel electrode were used as counter and reference electrodes, respectively. All the potentials given in this paper are relative to saturated calomel electrode (SCE). 


\section{Results and Discussion}

Figure 1 shows the change in the corrosion rates of the sputter-deposited W-Cr-(4-15)Ni alloys after immersion for $168 \mathrm{~h}$ in $1 \mathrm{M} \mathrm{NaOH}$ solution at $25^{\circ} \mathrm{C}$, open to air. The corrosion rates of the sputter-deposited $\mathrm{W}-(7-15) \mathrm{Ni}$ binary alloys, tungsten, chromium and nickel metals are also shown for comparison. The corrosion rates of tungsten, chromium and nickel are about $3.5 \times 10^{-1} \mathrm{~mm} \cdot \mathrm{y}^{-1}, 2.2 \times 10^{-2} \mathrm{~mm} \cdot \mathrm{y}^{-1}$ and $4.9 \times 10^{-3} \mathrm{~mm} \cdot \mathrm{y}^{-1}$, respectively. It is noteworthy to mention here that corrosion rates of the sputter-deposited binary $\mathrm{W}-7 \mathrm{Ni}, \mathrm{W}-$ $9 \mathrm{Ni}$ and $\mathrm{W}-15 \mathrm{Ni}$ alloys were about $3.0 \times 10^{-1}, 2.2 \times 10^{-1}$ and $2.1 \times 10^{-2} \mathrm{~mm} \cdot \mathrm{y}^{-1}$, respectively, in $1 \mathrm{M} \mathrm{NaOH}$ solution at $25^{\circ} \mathrm{C}$. ${ }^{11}$ Corrosion rates of the $\mathrm{W}-\mathrm{Cr}-(4-15) \mathrm{Ni}$ alloys containing 42-75 at\% chromium are about two orders of magnitude lower than those of the sputter-deposited $\mathrm{W}-(7-9) \mathrm{Ni}$ alloys and tungsten, and about one order of magnitude lower than those of sputter-deposited $\mathrm{W}-15 \mathrm{Ni}$ alloy and chromium metal in $1 \mathrm{M} \mathrm{NaOH}$ solution. These results clearly revealed that all the examined sputter-deposited $\mathrm{W}-\mathrm{Cr}-(4-15) \mathrm{Ni}$ alloys, which are composed of either amorphous or/and nanocrystalline single phase solid solution, show higher corrosion resistance than those of alloy-constituting elements (that is, tungsten, chromium and nickel) even for prolonged immersion in an aggressive $1 \mathrm{M} \mathrm{NaOH}$ solution at $25^{\circ} \mathrm{C}$. Consequently, the addition of chromium to the sputter-deposited binary W-Ni alloys is very effective in enhancing the corrosion resistance in alkaline $\mathrm{NaOH}$ solutions.

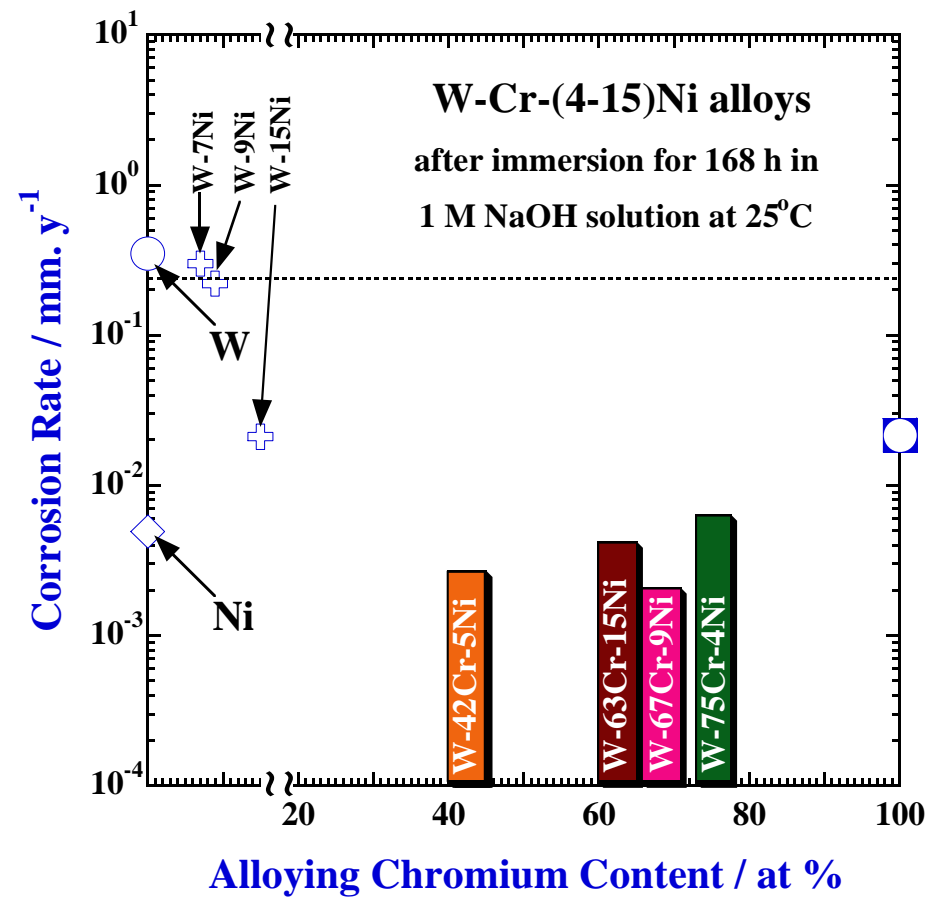

Figure 1: Changes in corrosion rates of W-Cr-(4-15)Ni alloys including W-(7-15)Ni alloys, tungsten, chromium and nickel metals in $1 \mathrm{M} \mathrm{NaOH}$ at $25^{\circ} \mathrm{C}$, open to air. 
In order to clarify the time dependence of corrosion rate of the sputter-deposited W-Cr(4-15) $\mathrm{Ni}$ alloys in alkaline $\mathrm{NaOH}$, the corrosion rates of the $\mathrm{W}-42 \mathrm{Cr}-5 \mathrm{Ni}, \mathrm{W}-63 \mathrm{Cr}-15 \mathrm{Ni}$ and $\mathrm{W}-75 \mathrm{Cr}-4 \mathrm{Ni}$ alloys were measured after immersion for various time intervals. Figure 2 shows the changes of corrosion rates of the W-Cr-(4-15)Ni alloys including chromium metal in $1 \mathrm{M} \mathrm{NaOH}$ solution at $25^{\circ} \mathrm{C}$, as a function of immersion time. The corrosion rates of all the examined $\mathrm{W}-\mathrm{Cr}-(4-15) \mathrm{Ni}$ alloys and chromium metal are generally high at initial periods of immersion (for example, for about 2-24 h). The corrosion rate is decreased with immersion time till $48 \mathrm{~h}$ and after that the corrosion rates of $\mathrm{W}-\mathrm{Cr}-(4-15) \mathrm{Ni}$ alloys including chromium metal become nearly steady in $1 \mathrm{M} \mathrm{NaOH}$ solution at $25^{\circ} \mathrm{C}$.

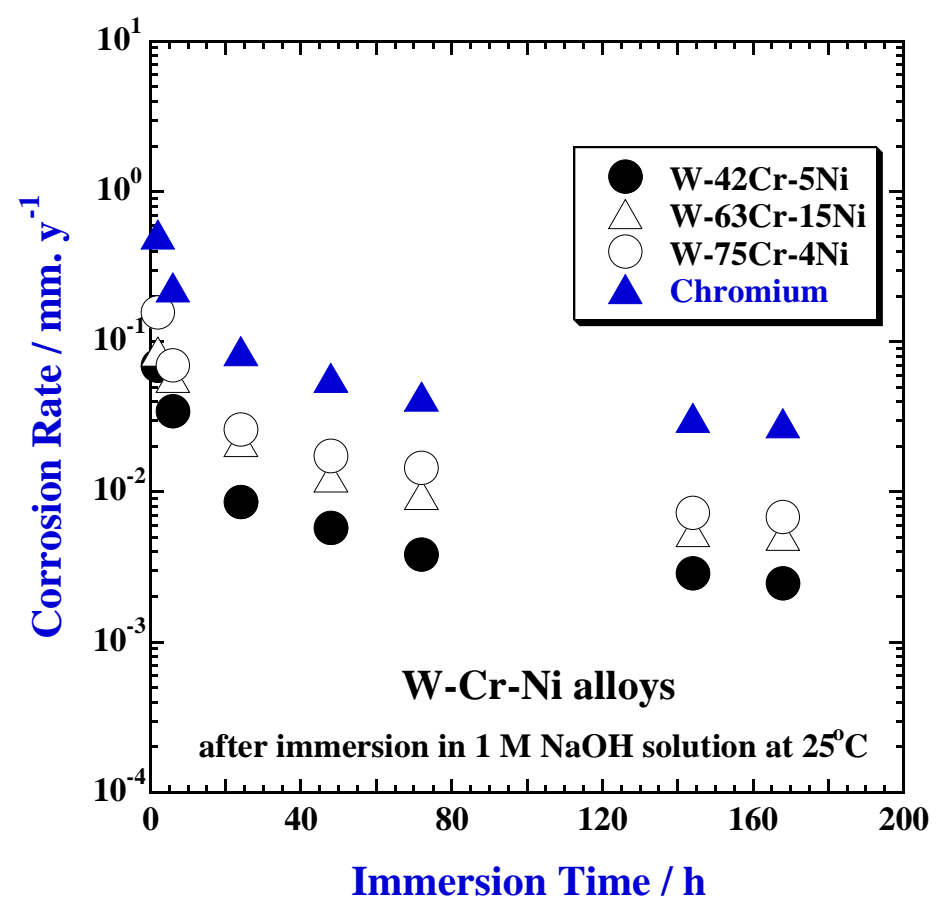

Figure 2: Changes in corrosion rates of $\mathrm{W}$-Cr-(4-15)Ni alloys and chromium metal in $1 \mathrm{M}$ $\mathrm{NaOH}$ at $25^{\circ} \mathrm{C}$, open to air as a function of immersion time.

Electrochemical measurements were carried out for a better understanding of the passivation behavior and high corrosion resistance properties of the sputter-deposited amorphous or nanocrystalline W-Cr-(4-15)Ni alloys in different concentration of $\mathrm{NaOH}$ solutions at $25^{\circ} \mathrm{C}$, open to air.

Figure 3 shows the changes in open circuit potentials for the sputter-deposited W-Cr-(415) $\mathrm{Ni}$ alloys including tungsten, chromium and nickel metals in $1 \mathrm{M} \mathrm{NaOH}$ solution at $25^{\circ} \mathrm{C}$, as a function of immersion time. The open circuit potential of the sputter-deposited chromium is about $-760 \mathrm{mV}$ (SCE) after immersion for 2 seconds and shifted very fast towards the more noble direction with immersion time and reached a potential of about -150 $\mathrm{mV}$ (SCE) after immersion for 2 hours. The similar behavior of the change of open circuit potential is shown for the nickel metal also. However, the open circuit potential of the 
sputter-deposited tungsten shifted very slightly towards more negative direction with immersion time and a steady state open circuit potential of about $-900 \mathrm{mV}$ (SCE) is attained after immersion for about 5 minutes. On the other hand, the open circuit potentials of all the examined W-Cr-(4-15)Ni alloys are found to shift towards more positive direction with immersion time. The open circuit potentials of $\mathrm{W}-63 \mathrm{Cr}-15 \mathrm{Ni}, \mathrm{W}-67 \mathrm{Cr}-9 \mathrm{Ni}$ and $\mathrm{W}-75 \mathrm{Cr}-4 \mathrm{Ni}$ alloys are located very close to those of nickel and chromium metals. However, the open circuit potential of the $\mathrm{W}-42 \mathrm{Cr}-5 \mathrm{Ni}$ alloy is in more negative direction than those of other $\mathrm{W}-\mathrm{Cr}-(4-15) \mathrm{Ni}$ alloys and located between those of the tungsten and chromium metals in 1 $\mathrm{M} \mathrm{NaOH}$ solution. These facts coincide with the change in the corrosion rates of the sputterdeposited amorphous or nanocrystalline $\mathrm{W}-\mathrm{Cr}-(4-15) \mathrm{Ni}$ alloys in $1 \mathrm{M} \mathrm{NaOH}$ solution as shown in figures 1 and 2.

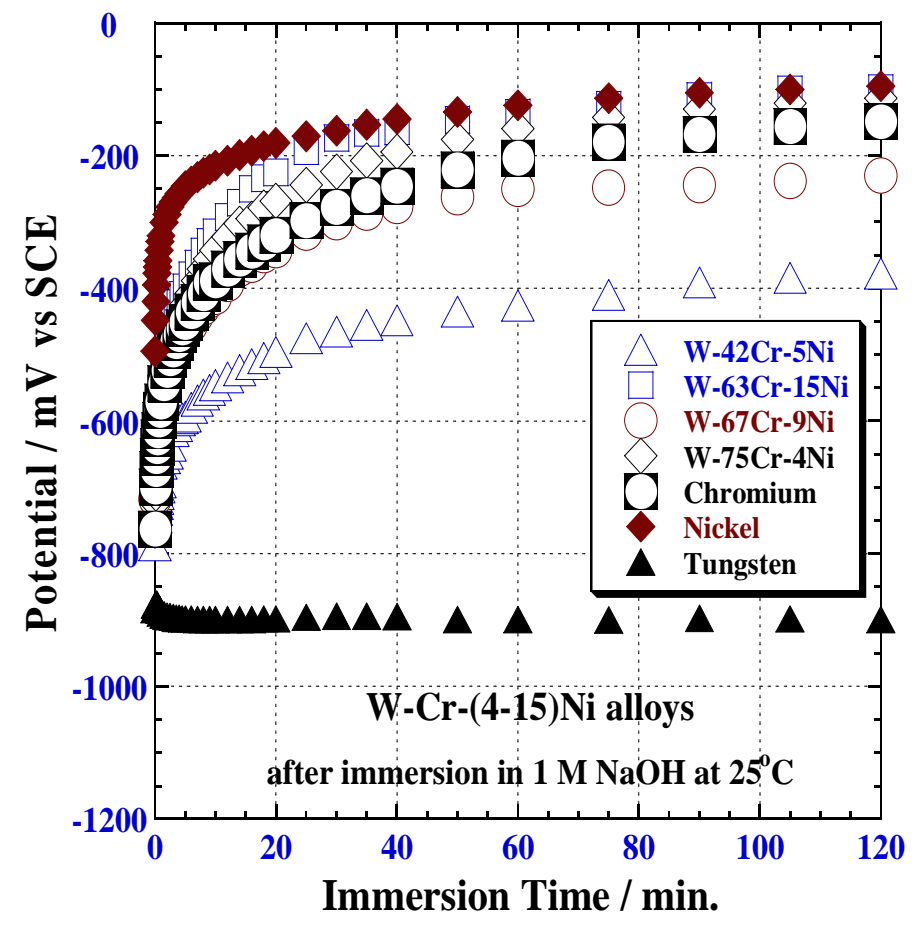

Figure 3: Changes in open circuit potentials for $\mathrm{W}$-Cr-(4-15)Ni alloys including tungsten, chromium and nickel metals in $1 \mathrm{M} \mathrm{NaOH}$ at $25^{\circ} \mathrm{C}$, as a function of immersion time.

Furthermore, figure 4 shows the changes in the open circuit potentials for the $\mathrm{W}-42 \mathrm{Cr}$ $5 \mathrm{Ni}, \mathrm{W}-63 \mathrm{Cr}-15 \mathrm{Ni}, \mathrm{W}-67 \mathrm{Cr}-9 \mathrm{Ni}$ and $\mathrm{W}-75 \mathrm{Cr}-4 \mathrm{Ni}$ alloys in different concentrations of $\mathrm{NaOH}$ solutions as a function of immersion time. In general, the open circuit potentials of all the examined $\mathrm{W}-\mathrm{Cr}-(4-15) \mathrm{Ni}$ alloys are shifted towards noble direction with decreasing the concentration of $\mathrm{NaOH}$ solutions. The similar behavior of the ennoblement of the open circuit potentials of the sputter-deposited tungsten, chromium and nickel were reported with different concentration of $\mathrm{NaOH}$ solutions at $25^{\circ} \mathrm{C}$. Consequently, the stability of the passive films formed on the sputter-deposited W-Cr-(4-15)Ni alloys increased with decreasing the concentrations of $\mathrm{NaOH}$ solutions at $25^{\circ} \mathrm{C}$. 

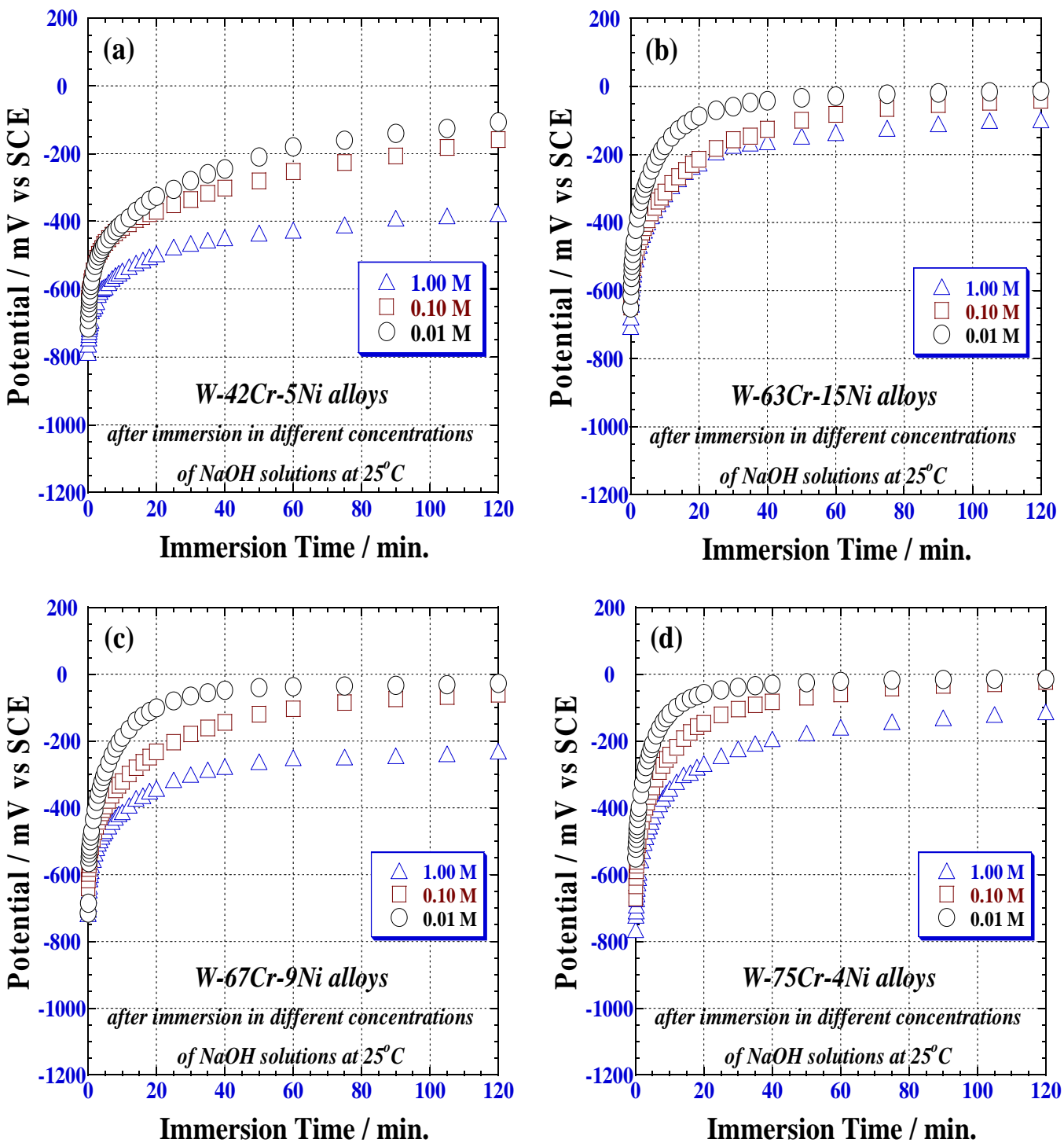

Figure 4: Changes in open circuit potentials for W-Cr-(4-15)Ni alloys in different concentrations of $\mathrm{NaOH}$ solutions at $25^{\circ} \mathrm{C}$, as a function of immersion time.

Figure 5 shows the changes in the corrosion rates and the open circuit potentials of the ternary amorphous or/and nanocrystalline W-Cr-(4-15) Ni alloys in $1 \mathrm{M} \mathrm{NaOH}$ solution, as a function of alloying chromium content. The open circuit potentials of the alloys are shifted to more positive direction with increasing the chromium content in the ternary W-Cr-Ni alloys, and hence the alloys containing 63-75 at\% chromium show the most noble open circuit potential than those of $\mathrm{W}-42 \mathrm{Cr}-5 \mathrm{Ni}$ alloy, tungsten and chromium metals. This revealed that high corrosion resistance of the ternary $\mathrm{W}-\mathrm{Cr}-(4-15) \mathrm{Ni}$ alloys is mostly due to the ennoblement of the open circuit potential of the alloys in $1 \mathrm{M} \mathrm{NaOH}$ solution at $25^{\circ} \mathrm{C}$. 


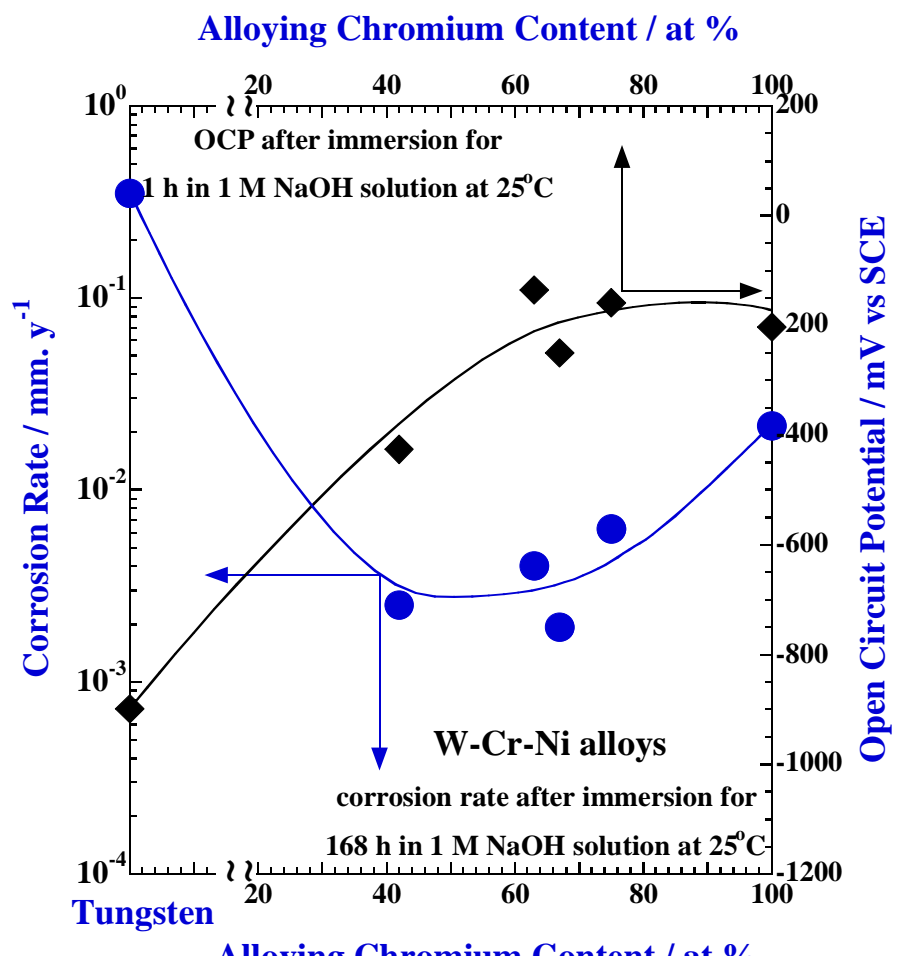

Alloying Chromium Content / at \%

Figure 5: Changes in corrosion rates and open circuit potentials of $\mathrm{W}$-Cr-(4-15)Ni alloys after immersion in $1 \mathrm{M} \mathrm{NaOH}$ at $25^{\circ} \mathrm{C}$, as a function of alloying chromium content.

\section{Conclusions}

The effect of chromium on the corrosion behavior of the W-Cr-(4-15)Ni alloys is studied in different concentrations of $\mathrm{NaOH}$ solutions at $25^{\circ} \mathrm{C}$, open to air using corrosion tests and electrochemical measurements. The following conclusions are drawn:

1. All the examined sputter-deposited W-Cr-(4-15)Ni alloys, which are composed of either amorphous or nanocrystalline single phase solid solution, show higher corrosion resistance than those of alloy-constituting elements (that is, tungsten, chromium and nickel) in an alkaline $1 \mathrm{M} \mathrm{NaOH}$ solution at $25^{\circ} \mathrm{C}$, and hence the synergistic effect of chromium addition in enhancing the corrosion resistance of the W-Cr-(4-15)Ni alloys is clearly observed in alkaline $\mathrm{NaOH}$ solutions.

2. The open circuit corrosion potential of the W-Cr-(4-15)Ni alloys is generally increased with increasing chromium contents in the alloys.

3. The passivity of the alloys is increased with dilution of $\mathrm{NaOH}$ solution at $25^{\circ} \mathrm{C}$. 


\section{Acknowledgements}

Authors are thankful to the Central Department of Chemistry, Tribhuvan University, Kirtipur for providing us the research facilities to conduct this research work.

\section{References}

1. H. H. Uhlig and R. Winston Revie, in Corrosion and Corrosion Control, $3^{\text {rd }}$ edition, 1991

2. J. Zarzycki, Materials Science and Technology; A Comprehensive Treatment (eds R. W. Chan, P. Haasen and E. J. Kramer), Vol. 9, VCH Publishers Inc., New York. 1991, p. 19.

3. K. Hashimoto, in Rapidly Solidified Alloys; Processes, Structures, Properties, Applications (eds. Howard H. Liebermann), Marcel Dekker Inc., New York. 1993, p. 591.

4. K. E. Heusler, D. Landolt and S. Trasatti, Pure and Appl. Chem.,1989, 61, 19.

5. J. Bhattarai, E. Akiyama, A. Kawashima, K. Asami and K. Hashimoto, Corros. Sci., 1998, 40, 155.

6. J. Bhattarai, The Corrosion Behavior of Sputter-deposited Tungsten-base Alloys.

Research Reports, Institute for Materials Research (IMR), Tohoku University, Sendai, Japan. 1995, pp. 43+IV.

7. J. Bhattarai, J. Nepal Chem. Soc., 2001, 20, 24.

8. J. Bhattarai, Scientific World, 2009, 7, 6.

9. J. Bhattarai, E. Akiyama, H. Habazaki, A. Kawashima, K. Asami and K. Hashimoto, Corros. Sci., 1998, 40, 155.

10. J. Bhattarai, 2002. J. Inst. Sci. Technol., 2002, 12, 125.

11. J. Bhattarai, S. P. Sah and H. Jha, J. Nepal Chem. Soc., 2007, 22, 7.

12. M. Pourbaix, in Atlas of Electrochemical Equilibrium in Aqueous Solution, National Association of Corrosion Engineers Huston, TX. 1974, p. 256.

13. M. Pourbaix, in Atlas of Electrochemical Equilibrium in Aqueous Solution, National Association of Corrosion Engineers Huston, TX. 1974, p. 334.

14. M. Pourbaix, in Atlas of Electrochemical Equilibrium in Aqueous Solution, National Association of Corrosion Engineers Huston, TX. 1974, p. 280. 